14 Boman G, Bäcker U, Larsson S, Melander B, Wählander L. Oral acetylcysteine reduces exacerbation rate in chronic bronchitis: report of a tria organised by the Swedish society for pulmonary diseases. Eur 7 Respir Dis 1983;64:405-15.

15 Cockcroft DW, Killian DN, Mellon JJA, Hargreave FE. Bronchial reactivity to inhaled histamine; a method and clinical survey. Clin Allergy 1977;7 237-43.

16 Dompeling E, van Schayck CP, Folgering H, van den Hoogen HJM, van Weel C. Accuracy, precision and linearity of the portable flow-volume mete Microspiro HI-298. Eur Respir $\mathcal{J}$ 1991;4:612-5.

17 Hunt SM, McEwen J, McKenna SP. Measuring health status: a new tool for clinicians and epidemiologists. 7 R Coll Gen Pract. 1985;35:185-8.

18 Pocock SJ. Clinical trials. A practical approach. London: John Willey, 1983:114-9,176-86.
19 Burrows B, Bloom JW, Traver GA, Cline MG. The course and prognosis of different forms of chronic airways obstruction in a sample from the general population. N Engl f Med 1987;317:1309-14.

20 Sanjar S, Morley J. Airway hyperreactivity. Lancet 1988;ii:160-1.

21 Barnes PJ. Effect of corticosteroids on airway hyperresponsiveness. Am Rev Respir Dis 1990;141:S70-6.

22 Weir DC, Sherwood Burge P. Use of corticosteroids in patients with chronic airflow obstruction by physicians in the west Midlands. Thorax 1990;45:791.

23 British Thoracic Society. Guidelines for management of asthma in adults. I. Chronic persistent asthma. BMF 1990;301:651-3.

24 Crompton GK. $\beta_{2}$-agonists in asthma. Lancet 1991;337:43-4.

\title{
Elective total hip replacement: incidence, emergency readmission rate, and postoperative mortality
}

\author{
Valerie Seagroatt, Heng Soon Tan, Michael Goldacre, Christopher Bulstrode, Ian Nugent, \\ Leicester Gill
}

\section{Abstract}

Objectives-To report the incidence of elective total hip replacement and postoperative mortality, emergency readmission rates, and the demographic factors associated with these rates in a large defined population.

Design-Analysis of linked, routine abstracts of hospital inpatient records and death certificates.

Setting-10 hospitals in six districts in Oxford Regional Health Authority covered by the Oxford record linkage study.

Subjects-Records for 11607 total hip replacements performed electively in 1976-85.

Main outcome measures-Incidence of operation, postoperative mortality, relative mortality ratios, and incidence of emergency readmission.

Results-NHS operation rates increased over time from 43 to 58 operations $/ 100000$ population Variation in operation rates between districts reduced over time. Operation rates were on average $25 \%$ higher in women than men. There were 93 deaths (11/1000 operations) within 90 days of the operation and 208 emergency readmissions $(28 / 1000$ operations) within 28 days of discharge. Postoperative mortality and emergency readmission rates increased with age. No significant trend with time was found. Mortality in the 90 days after the operation was 2.5 -fold higher $(1.9$ to 3.0$)$ than in the rest of the first postoperative year. This represented an estimated excess of $6.5(4.2$ to 8.8$)$ early postoperative deaths/1000 operations. Most deaths were ascribed to cardiovascular events. Thromboembolic disease was the commonest reason for emergency readmission.

Conclusions - The pronounced increase in operations in districts with initially low rates suggests a trend towards greater equity in the local provision of NHS hip arthroplasty. The early postoperative clusters of deaths attributed to cardiovascular disease and of readmissions for thromboembolic disease suggest that there is scope for investigating ways of reducing the incidence of major adverse postoperative events.

\section{Introduction}

Hip arthroplasty is one of the most common and successful major elective operations. People waiting for hip operations in England constitute an importan component of waiting lists, and the Department of Health has established targets for operation rates in health authorities. ${ }^{1}$ Descriptive studies of the epidemiology of hip arthroplasty have been published but, particularly the studies of outcome, have generally come from individual specialist centres or been based on fairly small numbers of operations. ${ }^{2-13}$ A modest amount of routine information about rates of hip arthroplasty in England has been published in the Hospital In-patient Enquiry. ${ }^{14}$ In addition, a review ${ }^{\omega}$ article on assessing the need for total hip replacements $O$ has recently been published. ${ }^{15}$ But there is no routine statistical information available about readmissions or deaths after the operation. We used the Oxford record ${ }_{\varnothing}^{\infty}$ linkage study to report operation rates, postoperative mortality, and readmission rates in a large, defined population. As these data show that postoperative mortality varies considerably depending on whether $\vec{\emptyset}$ the arthroplasty is elective or the result of an emergency. admission, this report is confined to elective hip arthroplasty; our findings on post-traumatic operations will be reported elsewhere.

\section{Methods}

RECORDS

The Oxford record linkage study is a collection of computerised abstracts of hospital records and death certificates collected such that data on successive events relating to the same patient can be linked together. Death records were available for all patients in the study area regardless of place of death. We 3 analysed data on hospital admissions in 1976-85, when data collection was undertaken in six districts of the Oxford region, covering a resident population of 1.9 million. The record linkage study collects data on all patients admitted to hospital for NHS care. Hospitals on that treat private patients have been invited to submit $D$ data, but their submission of data on private care has been inconsistent. Unless otherwise indicated the results in this study refer to NHS operations only.

All records that included the Office of Population Censuses and Surveys operation code for total hip replacement (810) were identified. ${ }^{16}$ Unfortunately only a few hospitals used the optional code $(810 \cdot 5)$ to distinguish between primary and revision replacements. Patients with femoral fracture were excluded. A validation study of coding was undertaken in one hospital, which performed about half the hip replace- $\mathbb{D}$ ments in the region, by cross checking between the record linkage study files and the hospital's operating theatre registers.

All hip replacements undertaken in the six districts were included in the calculations of incidence of the흘 operation. In the analysis of postoperative mortality ? patients who had had a second operation in the 90 days after a first arthroplasty were excluded, so all the 
patients in the study had a full 90 days' follow up of the first operation. Postoperative mortality data therefore relate to deaths within 90 days after the first recorded operation. When patients were transferred to another hospital after the operation the second episode of care was linked with the first and the data of eventual discharge used in calculating times from discharge to readmission. ${ }^{17}$

\section{STATISTICAL METHODS}

Rates were standardised by the indirect method, taking the rates for all hip replacements performed during the study period as the standard rates. Rates were age standardised when men and women were considered separately, and otherwise they were age and sex standardised.

Postoperative mortality was calculated by using the number of deaths after operation as the numerator and the number of operations as the denominator. The age and sex standardised postoperative mortality was compared between groups of patients by log linear models fitted by the generalised linear interactive model computer package. ${ }^{18}$ (The observed values were taken as the dependent variable and the expected values as offsets.) After inspection of plots of times from operation to death 90 days was chosen as the follow up time (see fig 2) as most of the deaths due to the operation or factors associated with it were likely to have occurred within that period.

To assess the extent to which the operation resulted in excess mortality we first calculated the average total mortality for the period 91 to 364 days after the operation by the life table method and took this as an estimate of the background mortality in this population. We then determined the number of deaths which would have been expected in the first 90 days after operation had this rate prevailed. The ratio of observed to expected numbers of deaths within 90 days was calculated and termed the relative mortality ratio. Confidence intervals were calculated on the assump-

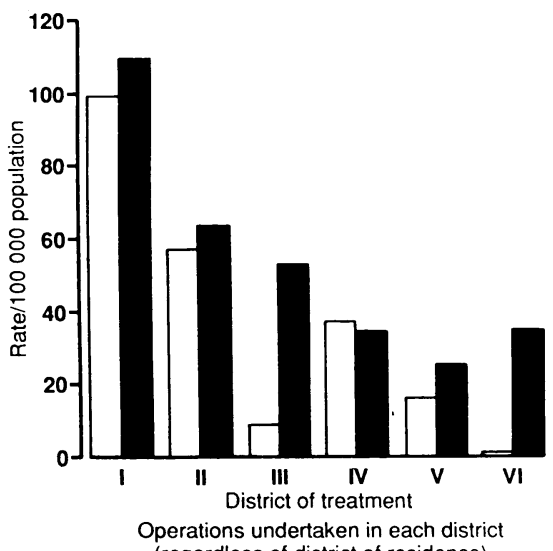
(regardless of district of residence)

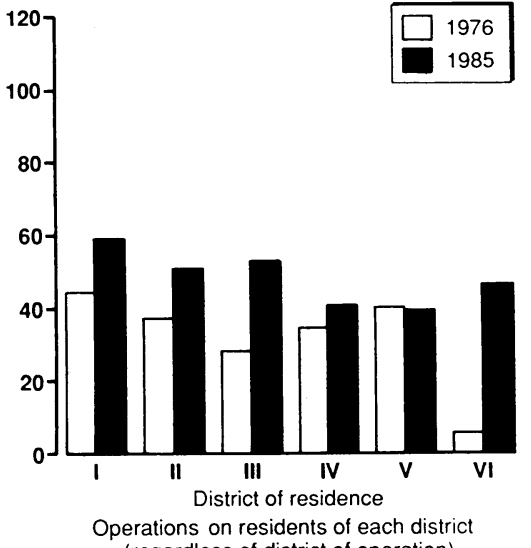

(regardless of district of operation)
FIG 1 -Elective total hip replacement rates for operations undertaken in district and in district residents in 1976 and 1985

TABLE I-Age and sex specific total hip replacement rates/100000 population/year for patients treated in Oxford record linkage study area

\begin{tabular}{|c|c|c|c|c|c|}
\hline \multirow[b]{2}{*}{ Age (years) } & \multicolumn{2}{|c|}{ No of operations } & \multicolumn{2}{|c|}{ Average annual rates } & \multirow{2}{*}{$\begin{array}{l}\text { Rates in women: } \\
\text { rates in men }\end{array}$} \\
\hline & Men & Women & Men & Women & \\
\hline$<35$ & 93 & 133 & 1.6 & $2 \cdot 5$ & 1.52 \\
\hline $35-44$ & 141 & 137 & $10 \cdot 3$ & $10 \cdot 3$ & $1 \cdot 00$ \\
\hline $45-54$ & 371 & 496 & $31 \cdot 8$ & $43 \cdot 4$ & $1 \cdot 37$ \\
\hline $55-64$ & 1194 & 1445 & $117 \cdot 3$ & $136 \cdot 4$ & $1 \cdot 16$ \\
\hline $65-74$ & 1668 & 2639 & $232 \cdot 0$ & $303 \cdot 0$ & $1 \cdot 31$ \\
\hline $75-84$ & 651 & 1441 & $221 \cdot 3$ & $275 \cdot 1$ & $1 \cdot 24$ \\
\hline$\geqslant 85$ & 19 & 92 & $39 \cdot 4$ & 60.6 & 1.54 \\
\hline $\begin{array}{l}\text { Total } \\
\text { Age standardised value }\end{array}$ & 4144 & 6401 & $\begin{array}{l}40 \cdot 2 \\
44 \cdot 6\end{array}$ & $\begin{array}{l}61 \cdot 3 \\
55 \cdot 8\end{array}$ & $\begin{array}{l}1.53 \\
1.27\end{array}$ \\
\hline
\end{tabular}

*Includes 25 cases in which age was not recorded (seven men and 18 women).

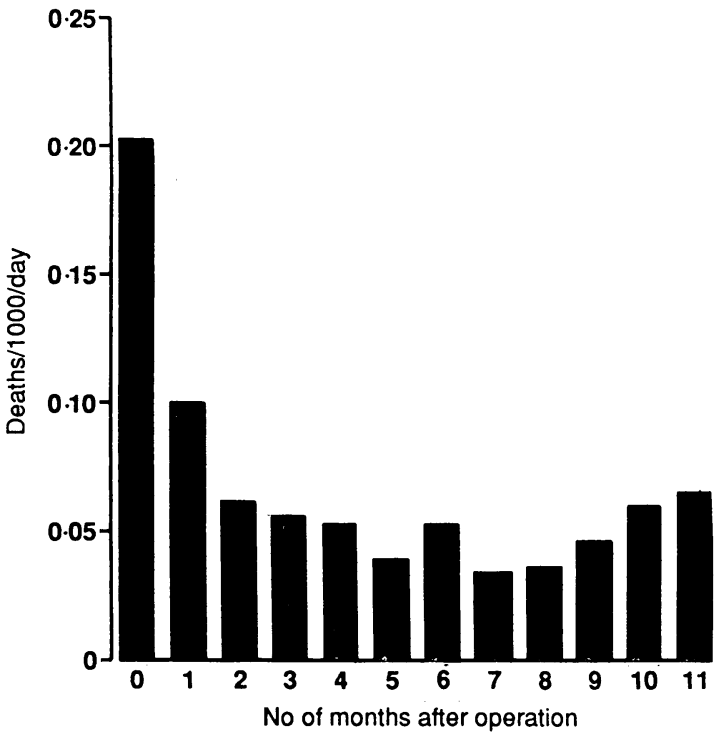

FIG 2-Death rate/1000 total hip replacements/day in year after operation

tion that the observed number of deaths was a Poisson variable. (This procedure ignores the error in determining the expected values and therefore gives an approximation.) The calculation of relative mortality ratios also enables comparisons to be made between excess postoperative deaths in subgroups of patientsfor example, patients in different age groups or different hospitals - in a way which takes account of differences in background mortality between the subgroups. In effect, data on patients in each subgroup act as a "control" in estimating excess early postoperative mortality in these patients.

Most emergency readmissions occurred within 28 days of discharge, so our data refer to readmissions within this period. Age and sex standardised readmission rates were compared between different subgroups by using $\log$ linear models in a similar way to that described for postoperative mortality.

\section{Results}

In the validation study carried out in one hospital 6158 records of total hip replacements were identified in the files of the Oxford record linkage study. Of these, $6087(98 \cdot 8 \%)$ were verified as total hip replacements in the operating theatre registers. Twenty seven records $(0.4 \%)$ were of other hip operations, $13(0.2 \%)$ were total knee replacements (often abbreviated to TKR and probably misread as THR), nine were other operations, and in 22 cases $(0 \cdot 4 \%)$ no record of an operation was found in the operating theatre registers. The hospital registers included 6377 total hip replacements during the period. The Oxford record linkage study omitted data for 290 operations $(4 \cdot 5 \%)$, of which 66 were known to have been undertaken privately.

In all, during 1976-85 the record linkage study had records of 9767 patients who underwent 11607 elective total hip replacements. Of these, 10545 hip replacements in 8895 patients were recorded as NHS operations. In 1976 the surgical workload rates for NHS operations undertaken in each district, regardless of patients' place of residence, varied from 1 to $98 / 100000$ people (fig 1). By 1985 the workload rates for operations undertaken in each district varied from 26 to 109 / 100000 people. If the data are expressed as population based rates for operations undertaken in residents of each district, regardless of where in the six districts the operation was performed, in 1976 operation rates varied from 6 to 45 operations $/ 100000$ people and by 1985 from 40 to 59 operations $/ 100000$ people. Overall, the rate of hip replacement in residents in the six 
TABLE II - Underlying causes of death within 90 days and from 91 to 364 days after total hip replacement and relative risk and excess risk of death within 90 days compared with rest of first postoperative year

\begin{tabular}{|c|c|c|c|c|c|c|}
\hline Cause of death ${ }^{\star}$ & $\begin{array}{c}\text { Deaths } \\
\text { within } 90 \\
\text { days }\end{array}$ & $\begin{array}{l}\text { Deaths } \\
\text { from } 91 \text { to } \\
364 \text { days }\end{array}$ & $\begin{array}{c}\text { Expected } \\
\text { deaths } \\
\text { within } 90 \\
\text { days }\end{array}$ & $\begin{array}{c}\text { Relative } \\
\text { risk } \\
\text { (observed/ } \\
\text { expected) }\end{array}$ & $\begin{array}{c}\text { Excess } \\
\text { deaths } \\
\text { (observed- } \\
\text { expected }\end{array}$ & $\begin{array}{c}\text { Excess } \\
\text { deaths/ } \\
1000 \\
\text { operations }\end{array}$ \\
\hline Ischaemic heart disease & 37 & 29 & $10 \cdot 17$ & $3 \cdot 64$ & $26 \cdot 8$ & $3 \cdot 15$ \\
\hline Stroke & 10 & 11 & $3 \cdot 86$ & 2.59 & $6 \cdot 1$ & $0 \cdot 72$ \\
\hline Venous thrombosis and embolism & 6 & 1 & 0.35 & $17 \cdot 11$ & $5 \cdot 7$ & 0.67 \\
\hline Other heart disease & 2 & 2 & $0 \cdot 70$ & $2 \cdot 85$ & $1 \cdot 3$ & $0 \cdot 15$ \\
\hline Pneumonia & 9 & 6 & $2 \cdot 10$ & $4 \cdot 28$ & 6.9 & $0 \cdot 81$ \\
\hline Other respiratory disease & 2 & 3 & 1.05 & 1.90 & $0 \cdot 9$ & $0 \cdot 11$ \\
\hline Musculoskeletal conditions & 14 & 6 & $2 \cdot 10$ & 6.65 & 11.9 & $1 \cdot 40$ \\
\hline Cancer & 3 & 27 & $9 \cdot 44$ & $0 \cdot 32$ & $-6 \cdot 4$ & 1 \\
\hline Complications of operation & 1 & 0 & 0 & 0 & 1 & $0 \cdot 12$ \\
\hline Other & 9 & 23 & $8 \cdot 05$ & $1 \cdot 12$ & $0 \cdot 9$ & $0 \cdot 11$ \\
\hline Total & 93 & 108 & $37 \cdot 82$ & $2 \cdot 46$ & $55 \cdot 19$ & 6.49 \\
\hline
\end{tabular}

$\star$ As coded as underlying cause on death certificate.

tCalculated by applying death rates at 91-364 days to people at risk at 0-90 days.

TABLE III -Number of deaths and postoperative mortality/1000 operations and relative mortality within 90 days of operation and number and rate/1000 operations of emergency readmissions within 28 days of discharge

\begin{tabular}{|c|c|c|c|c|c|c|c|}
\hline \multirow[b]{3}{*}{$\begin{array}{l}\text { Age } \\
\text { (years) }\end{array}$} & \multicolumn{4}{|c|}{ Deaths within 90 days } & \multirow{2}{*}{\multicolumn{3}{|c|}{ Emergency readmissions }} \\
\hline & \multirow[b]{2}{*}{$\begin{array}{c}\text { No of } \\
\text { patients }\end{array}$} & \multirow[b]{2}{*}{$\begin{array}{l}\text { No of } \\
\text { deaths }\end{array}$} & \multirow[b]{2}{*}{$\begin{array}{l}\text { Postoperative } \\
\text { mortality }\end{array}$} & \multirow{2}{*}{$\begin{array}{c}\text { Relative } \\
\text { mortality } \\
\text { ratio }\end{array}$} & & & \\
\hline & & & & & $\begin{array}{c}\text { No of } \\
\text { patients }\end{array}$ & $\begin{array}{c}\text { No of } \\
\text { readmissions }\end{array}$ & Rate \\
\hline \multicolumn{8}{|c|}{ Men } \\
\hline$<45$ & 166 & 0 & 0 & 0 & 145 & 2 & 14 \\
\hline 45-54 & 296 & 1 & $3 \cdot 4$ & 2.9 & 271 & 3 & 11 \\
\hline $55-64$ & 937 & 8 & $8 \cdot 5$ & $2 \cdot 8$ & 817 & 22 & 27 \\
\hline $65-74$ & 1361 & 16 & 11.8 & 1.8 & 1197 & 42 & 35 \\
\hline $75-84$ & 537 & 19 & $35 \cdot 4$ & 3.0 & 457 & 20 & 44 \\
\hline$\geqslant 85$ & 18 & 2 & $111 \cdot 1$ & $>10$ & 13 & 2 & 154 \\
\hline Total & 3315 & 46 & $15 \cdot 7^{\star}$ & $2 \cdot 38$ & $2900 \dagger$ & 91 & $33^{\star}$ \\
\hline
\end{tabular}

\begin{tabular}{lrrrrrrr}
\multicolumn{7}{c}{ Women } \\
$<45$ & 148 & 0 & 0 & 0 & 128 & 3 & 23 \\
$45-54$ & 396 & 1 & $2 \cdot 5$ & $0 \cdot 9$ & 356 & 8 & 22 \\
$55-64$ & 1166 & 3 & $2 \cdot 6$ & $1 \cdot 4$ & 1055 & 21 & 20 \\
$65-74$ & 2171 & 16 & $7 \cdot 4$ & $2 \cdot 3$ & 1947 & 47 & 24 \\
$75-84$ & 1233 & 24 & $19 \cdot 5$ & $3 \cdot 0$ & 1092 & 33 & 30 \\
$\geqslant 85$ & 79 & 3 & $58 \cdot 0$ & $8 \cdot 5$ & 69 & 5 & 72 \\
\hline Total & 5193 & 47 & $8 \cdot 4^{\star}$ & $2 \cdot 54$ & $4647 \dagger$ & 117 & $25^{\star}$ \\
\hline
\end{tabular}

$\star$ Age standardised rates.

tExcludes patients who died in index admission and all operations undertaken at one hospital.

districts rose from 43 to 58 operations/100 000 people between 1976 and 1985 .

Table I gives the age specific operation rates for men and women. Operation rates increased with age up to 75 years and declined thereafter. Rates were, on average, about $25 \%$ higher in women than in men. In 206 patients $(2 \cdot 0 \%$ of the total $)$ no underlying diagnosis was recorded. Of the remaining 10339 cases, osteoarthritis was the recorded diagnosis in $8726(84 \cdot 4 \%)$, rheumatoid arthritis in $579(5 \cdot 6 \%)$, and various other specified and symptomatic conditions relating to the musculoskeletal system in the remainder.

For the analyses of postoperative mortality and readmission rates we excluded operations undertaken in patients living outside the record linkage study area (1904), those performed within 90 days of earlier hip replacements (116), and those for which the patients' ages were not recorded (17). This left 8508 operations.

\section{DEATHS AFTER TOTAL HIP REPLACEMENT}

Death rates in the first month after operation, and to a lesser extent in the next two months, were higher than those in the subsequent nine months (fig 2). The risk of death from all causes in the first 90 days postoperatively was $2.5(95 \%$ confidence interval 1.9 to 3.0) times higher than that in comparable periods during the rest of the first postoperative year (table II). This represented $6.5(4.2$ to 8.8$)$ deaths/1000 operations. Ischaemic heart disease was the single commonest ascribed underlying cause of death. Venous thrombosis and embolism were less common causes of death but nevertheless had a high relative risk of death and accounted for an estimated excess of 0.7 deaths/ 1000 operations.

Postoperative mortality was strikingly lower in women than in men (table III): the ratio of age standardised rates was 0.53 (95\% confidence interval $0 \cdot 3$ to $0 \cdot 8$ ). In contrast the relative mortality ratios, which adjust for differences in underlying death rates between men and women were similar and had a corresponding ratio of $1 \cdot 07(0.7$ to $1 \cdot 6)$. Postoperative $\overrightarrow{\vec{F}}$ mortality declined by an average of $2.9 \%$ a year $(-9 \cdot 8 \%$ to $4 \cdot 4 \%)$ during the 10 year period studied, but this decline was not significant. The relative mortality ratios showed no decline (average change of $0.0 \%$ per year; $-6 \cdot 6 \%$ to $7 \cdot 2 \%$ ).

The age and sex standardised postoperative ${ }^{\circ}$ mortality was 1.29 times higher $(0.8$ to 2.0$)$ in patients $\vec{\circ}$ who underwent operation in the district general hospitals than those who were operated on in the $\vec{\omega}$ teaching hospital (table IV). When the relative mortality ratios were compared, the corresponding 3 ratio decreased slightly to $1.21(0.9$ to 2.1$)$. Neither $\dot{\omega}$ measure of difference between the types of hospitals $c$ was significant. Table IV also shows the age and sex $\infty$ standardised postoperative mortality and relative $\vec{v}$ mortality ratios for the individual hospitals. Postoperative mortality had a $4 \cdot 8$-fold range and the relative $\vec{\omega}$ mortality ratio a $3 \cdot 2$-fold range. However, neither of these variations between hospitals was significant $\left(\chi^{2}=6.9\right.$ and 8.5 respectively; $\left.\mathrm{df}=8 ; \mathrm{p}>0.05\right)$.

\section{EMERGENCY READMISSION RATES}

In the calculation of readmission rates data on the 64 patients who died during admission in which the $\stackrel{\mathbb{T}}{\rightarrow}$ operation was performed were excluded. Operations $\vec{\bullet}$ carried out in one hospital which regularly transferred $\oplus$ some of its patients to private hospitals or nursing homes after a median stay in hospital of five days were also excluded as dates of eventual discharge from hospital after convalescence could not be determined. This left data on 7547 operations.

Figure 3 gives the distribution of emergency admissions by time after the operation. Numbers were $\overrightarrow{\overrightarrow{0}}$ considerably higher in the first two weeks after discharge and reached a steady state by about four weeks after discharge. In all, 208 patients (28/1000 operations) had an emergency readmission in the 28 days after discharge. Emergency readmissions for venous thrombosis and embolism are also indicated in figure 3 . These conditions were the main diagnoses in the 3 hospital record for 54 (26\%) of these readmissions and $\delta$ were the single commonest diagnostic group of conditions in the records of readmission.

Emergency readmission rates increased with age up to 75 years (table III) and were significantly lower in women than men $\left(\chi^{2}=4 \cdot 3 ; \mathrm{df}=1 ; \mathrm{p}<0.05\right)$. Readmis $-\frac{\mathrm{T}}{\mathrm{O}}$

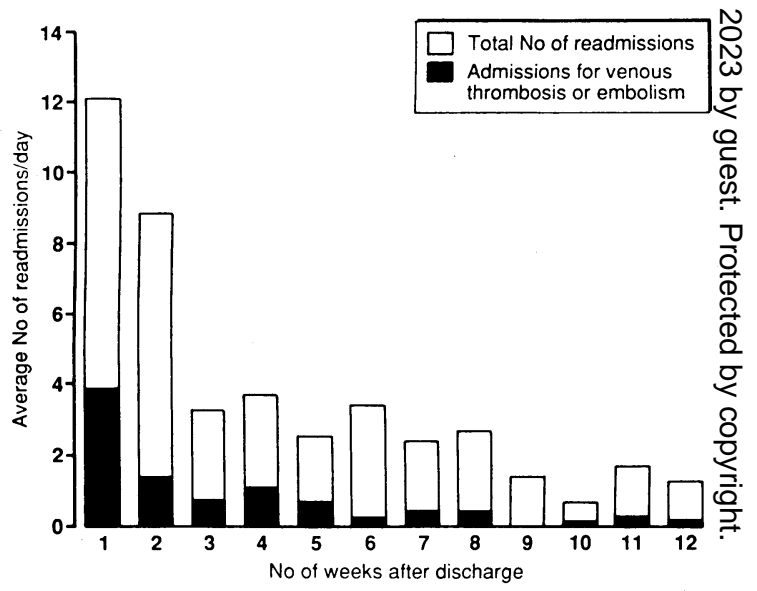

FIG 3-Number of emergency readmissions by time to readmission after discharge 
TABLE IV-Number of operations and deaths, postoperative mortality, relative mortality ratios, and emergency readmission within 28 days of discharge in teaching hospital and nine general hospitals. Figures are age and sex standardised rates/1000 operations

\begin{tabular}{|c|c|c|c|c|c|c|c|}
\hline \multirow[b]{3}{*}{ Hospital } & \multicolumn{4}{|c|}{ Deaths } & \multirow{2}{*}{\multicolumn{3}{|c|}{ Emergency readmissions }} \\
\hline & \multirow[b]{2}{*}{$\begin{array}{c}\text { No of } \\
\text { patients }\end{array}$} & \multirow[b]{2}{*}{$\begin{array}{l}\text { No of } \\
\text { deaths }\end{array}$} & \multirow[b]{2}{*}{$\begin{array}{l}\text { Postoperative } \\
\text { mortality }\end{array}$} & \multirow{2}{*}{$\begin{array}{l}\text { Relative } \\
\text { mortality } \\
\text { ratio }\end{array}$} & & & \\
\hline & & & & & $\begin{array}{c}\text { No of } \\
\text { patients }\end{array}$ & $\begin{array}{l}\text { No of } \\
\text { readmissions }\end{array}$ & $\begin{array}{l}\text { Standard } \\
\text { rate }\end{array}$ \\
\hline Teaching & 4008 & 36 & $9 \cdot 4$ & $2 \cdot 20$ & 3984 & 105 & $26 \cdot 6$ \\
\hline Otherst & 4500 & 57 & $12 \cdot 2$ & 2.66 & 3563 & 103 & $28 \cdot 7$ \\
\hline Hospital 1 & 4008 & 36 & $9 \cdot 4$ & $2 \cdot 20$ & 3984 & 105 & $26 \cdot 6$ \\
\hline Hospital 2 & 953 & 10 & $10 \cdot 4$ & 2.57 & 945 & 28 & $29 \cdot 6$ \\
\hline Hospital 3 & 905 & 9 & $9 \cdot 4$ & 1.84 & & & \\
\hline Hospital 4 & 636 & 11 & $16 \cdot 4$ & $4 \cdot 51$ & 628 & 17 & $26 \cdot 5$ \\
\hline Hospital 5 & 619 & 9 & $12 \cdot 8$ & 2.83 & 613 & 24 & 38.0 \\
\hline Hospital 6 & 606 & 8 & 13.8 & 4.55 & 602 & 16 & $26 \cdot 6$ \\
\hline Hospital 7 & 348 & 6 & 18.9 & 1.89 & 345 & 9 & $26 \cdot 8$ \\
\hline Hospital 8 & 227 & 1 & 3.9 & 1.44 & 226 & 8 & $33 \cdot 8$ \\
\hline Hospital 9 & 143 & 2 & 11.5 & $2 \cdot 83$ & 142 & 0 & 0 \\
\hline Hospital 10 & 61 & 1 & $15 \cdot 6$ & 1.41 & 60 & 1 & $16 \cdot 5$ \\
\hline
\end{tabular}

^Excludes cases where patient died in index admission and operations undertaken in hospital 3. fIncludes two cases where hospital was not recorded.

sion rates rose over time by an average rate of change of $3.4 \%$ per year $(95 \%$ confidence interval $-1.6 \%$ to $8 \cdot 8 \%$ ), but this was not significant. Table IV shows the readmission rates for the individual hospitals. The rates for the district general hospitals were, on average, 1.07 higher $(0.8$ to 1.4$)$ than those for the teaching hospital but the difference was not significant, nor was the twofold variation in readmission rates between individual hospitals $\left(\chi^{2}=12 \cdot 8 ; \mathrm{df}=8 ; \mathrm{p}>0.05\right)$.

\section{Discussion}

COMPLETENESS OF DATA

Medical record linkage provides a useful method for studying the incidence and prognosis of clinical interventions when, as with the data presented here, the intervention occurs in a setting where record abstracts are routinely collected and linkable and when outcomes like emergency readmission and death are readily recorded and identifiable. However, sèveral limitations of the data available for this study need consideration. No data were available on residents of the six districts covered by record linkage who were treated outside them. Information about cross boundary care is available for orthopaedic patients as a whole from data used administratively for allocating financial resources under the resource allocation working party formula. These data show that net flows of patients across the boundaries of this area were small during the time of the study. Thus our population rates for NHS operations are likely to be reasonably accurate.

The fact that data on most operations in the private sector were not available means that our rates underestimate the true incidence of total hip replacements. The percentages of hip replacements performed privately in England and Wales have been estimated to be $26.2 \%$ in $1981^{19}$ and $27.7 \%$ in $1985 . .^{20}$ No data are readily available for the 1970 s but the percentage is likely to be considerably lower. The coding of total hip replacement did not permit the distinction to be made between primary and revision arthroplasty. We are therefore unable to report on the longevity of primary or revision replacements. Coding of hip arthroplasty within the record linkage data was otherwise reliable.

The data on emergency readmission rates and postoperative mortality are probably slight underestimates because while readmissions would be identified to any hospital within the six districts (and not just to the hospital of operation), some patients may have been readmitted outside the area covered by record linkage. We believe this number to be small. Data on deaths should be virtually complete because the Oxford record linkage study receives death certificates for all people resident in its area regardless of place of death.
Death certificates are not received for patients who migrate permanently out of the area, but, at an estimated $2 \%$ a year, the effect of this on postoperative mortality within 90 days of care must be very small.

\section{DISTRICT VARIATIONS IN OPERATION RATES}

There were striking differences in the numbers of operations undertaken in each district, particularly in the early years of the study. Differences in operation rates in the residents of each district, taking account of cross boundary care, were less substantial and, by the later years of the study, population based operation rates had become much more similar between the districts. A substantial proportion of the overall increase in operation rates over time represented an increase in operations undertaken by districts with previously low rates and can be interpreted as a trend towards greater equity in the local provision by the NHS of hip arthroplasty operations.

\section{DEATHS ATTRIBUTABLE TO OPERATION}

Most patients who undergo elective hip arthroplasty are elderly and many probably have other medical conditions. Deaths in, say, the year after operation may be related to the operation or, particularly in elderly patients, may be independent of it. The plots of time from operation to death (fig 2) gave convincing evidence that total hip replacement was associated with excess deaths within the first three months after the operation. We assumed that the mortality observed after this time was independent of the operation and factors associated with it. The risk of death was 2.5 times higher in the 90 days after the operation than in the rest of the year. This represented an estimated excess of 6.5 deaths $/ 1000$ hip replacement operations.

The background risk of death may differ between subgroups of people. We therefore calculated the excess mortality in the first 90 days compared with the rest of the first postoperative year in men and women, people of different ages, in different calendar years, and for people treated in different hospitals (tables III and IV). For example, table III shows that the relative mortality ratios for men and women were similar. This suggests that the higher postoperative mortality in men and women probably did not result from the operation itself but reflects the fact that population based mortality is generally higher in men than women. The calculation of relative mortality ratios in this way allowed us to use patient groups as their own controls in estimating excess early postoperative mortality. It thus supplemented the information of postoperative mortality, which provides actual levels of death, while the relative mortality ratio provides an adjustment for background mortality in each group of people.

No significant differences in mortality were found between the teaching hospital and the district general hospitals when standardised postoperative mortality and relative mortality ratios were compared. Fortunately, few deaths occurred after the operation, bu this did limit the precision of this comparison. However, any true difference in mortality was unlikely to be greater than twofold. There was no evidence that either measure of outcome was related to the number of total hip replacements performed in each hospital.

\section{CONCLUSIONS}

During the 10 year period of this study there was no significant change in postoperative mortality. Rates for emergency readmissions increased with age, did not change substantially over time, and did not vary significantly between hospitals.

Most of the early excess of postoperative deaths was ascribed to cardiovascular causes. Although relatively few deaths were due to thromboembolic disease, this was a noteworthy cause of death because the relative 
risk of death associated with it was high. It was also the commonest single recorded reason for emergency readmissions. Recently it has been emphasised that early mobilisation after hip replacement reduces the incidence of postoperative thromboembolic disease. ${ }^{21}$ Investigation of the possibility of further reduction in postoperative deaths from circulatory disease in general, and perhaps thromboembolic disease in particular, is warranted.

The unit of clinical epidemiology is part of the department of public health and primary care at the University of Oxford and is funded by the Department of Health. The Oxford record linkage study is funded by Oxford Regional Health Authority. We thank Hugh Simmons and Margaret Godden for extracting data from the Oxford record linkage study files, Kate Hey for drawing the original figures, and Pamela Evans and Penny Buddenhagen for typing the manuscript.

1 Wroblewski BM. Charnley low-friction arthroplasty. Review of the past, present status, and prospects for the future. Clin Orthop 1986;201;:37-42.

2 Cornell CN, Ranawat CS. Survivorship analysis of total hip replacements. Results in a series of active patients who were less than fifty five years old. f Bone foint Surg [Am] 1986;68:1430-4.

3 Gustilo RB, Burnham WH. Long-term results of total hip arthroplasty in young patients. In: Nelson JP, ed. The hip. Proceedings of the tenth open young patients. In: Nelson JP, ed. The hip. Proceedings of the tenth
scientific meeting of the Hip Society. St Louis: CV Mosby, 1982:27-33.

4 Terayama K. Experience with Charnley low-friction arthroplasty in Japan. Clin Orthop 1986;211:79-84.

5 Wroblewski BM. 15-21-year results of the Charnley low-friction arthroplasty. Clin Orthop 1986;211:30-5.
6 Chandler HP, Reineck FT, Wixson RL, McCarthy JC. Total hip replacement in patients younger than thirty years old. A five year follow-up study. 7 Bone in patients younger than thirty yeas
foint Surg $[A m] 1981 ; 63: 1426-34$.

7 Dorr LD, Takei GP, Conaty JP. Total hip arthroplasty in patients less than forty-five years old. F Bone foint Surg (Am) 1983;65: 474-9.

8 Ranawat CS, Atkinson RE, Salvati EA, Wilson PD. Conventional total hip arthroplasty for degenerative joint disease in patients between the ages of forty and sixty years. F Bone foint Surg [Am] 1984;66:745-52.

9 Welch RB, McGann WA, Picetti GD. Charnley low-friction arthroplasty. A fifteen to seventeen year follow-up study. Orthop Clin North Am 1988;19: 551-5.

10 Brady LP, McCutchen JW. A ten-year follow-up study of 170 Charnley total hip arthroplasties. Clin Orthop 1986;211:51-4.

1 Charnley J. Fracture of femoral prostheses in total hip replacement. A clinical study. Clin Orthop 1975;111:105-20.

12 Older J. Low-friction arthroplasty of the hip. A 10-12-year follow-up study Clin Orthop 1986;211:36-42.

13 Salvati EA, Wilson PD, Jolley MN, Vakili F, Aglietti F, Brown GC. A ten year follow up-study of our first one-hundred consecutive Charnley total hip replacements. F Bone foint Surg [Am] 1981;62:753-67.

14 Department of Health and Social Security. Hospital In-patient Enquiry. London: HMSO. (Annual from 1955 to 1985 .)

15 Frankel W, Williams M, Nanchahal K, Coast J. Total hip and knee joint ڤొ replacement. Bristol: University of Bristol, 1991. (DHA project, report 2.) 6 Classification of surgical operations. 3rd Revision. London: Office of Population Censuses and Surveys, 1975

17 Henderson J, Goldacre MJ, Graveney MJ, Simmons HM. Use of medical records linkage to study readmission rates. BMF 1989;299:709-13.

18 Baker RJ, Nelder JA. The GLIM system release 3. Oxford: Numerical Algorithms Group, 1978.

19 Nicholl JP, Thomas KJ, Williams BT, Knowelden J. Contribution of the private sector to elective surgery in England and Wales. Lancet 1984;ii:

20 Nicholl JP, Beeby NR, Williams BT. Role of private sector in elective surgery in England and Wales, 1986. BMf 1989;298:243-7.

21 Lassen MR, Borris LC. Mobilisation after hip surgery and efficacy of $\vec{G}$ thromboprophylaxis. Lancet 1991;337:618.

(Accepted 25 September 1991 )

\title{
Cost effectiveness of magnetic resonance imaging in the neurosciences
}

\author{
A K Szczepura, J Fletcher, J D Fitz-Patrick
}

\begin{abstract}
Objectives-To measure, in a service setting, the effect of magnetic resonance imaging on diagnosis, diagnostic certainty, and patient management in the neurosciences; to measure the cost per patient scanned; to estimate the marginal cost of imaging and compare this with its diagnostic impact; to measure changes in patients' quality of life; and to record the diagnostic pathway leading to magnetic resonance imaging.
\end{abstract}

Design-Controlled observational study using questionnaires on diagnosis and patient management before and after imaging. Detailed costing study. Quality of life questionnaires at the time of imaging and six months later. Diagnostic pathways extracted from medical records for a representative sample.

Setting-Regional superconducting $1.5 \quad T$ magnetic resonance service.

Subjects -782 consecutive neuroscience patients referred by consultants for magnetic resonance imaging during June 1988-9; diagnostic pathways recorded for 158 cases.

Main outcome measures-Costs of magnetic resonance imaging and preliminary investigations; changes in planned management and resulting savings; changes in principal diagnosis and diagnostic certainty; changes in patients' quality of life.

Results-Average cost of magnetic resonance imaging was estimated at $£ 206.20$ /patient (throughput 2250 patients/year, 1989-90 prices including contrast and upgrading). Before magnetic resonance imaging diagnostic procedures cost $£ 164.40 /$ patient (including inpatient stays). Management changed after imaging in $208(27 \%)$ cases; saving an estimated $£ 80.90$ /patient. Confidence in planned management increased in a further $226(29 \%)$.referrals. Consult- ants' principal diagnosis changed in 159 of $782(20 \%)$ referrals; marginal cost per diagnostic change was £626. Confidence in diagnosis increased in $236(30 \%)$ referrals. No improvement in patients' quality of life 0 at six month assessment.

Conclusions - Any improvement in diagnosis with magnetic resonance imaging is achieved at a higher cost. Techniques for monitoring the cost effectiveness of this technology need to be developed.

\section{Introduction}

Magnetic resonance imaging is recognised as a potentially useful,,$^{1-6}$ although expensive, ${ }^{7-9}$ imaging technique. Early evaluations of its clinical benefits have been criticised recently, ${ }^{10-12}$ and its clinical $\stackrel{5}{5}$ efficacy still has to be rigorously shown. ${ }^{13-16}$ Mean- $N$ while, clinicians and managers are faced with decisions $D$ on when and how to introduce this new medical technology. ${ }^{17}$

In 1988 the West Midlands region opened its first N magnetic resonance imaging service, based in Coventry. It was expected that the main user would be the neurosciences, ${ }^{418-20}$ and that demand would outstrip supply. Therefore, population based quotas were $\cong$ allocated to each of the region's four neuroscience 0 centres. In addition, a service evaluation was commissioned to measure the extent to which magnetic $\mathbb{\mathbb { D }}$ resonance imaging in routine neuroscience clinical $\mathbb{D}$ practice is worth its costs. As a result a large database $\frac{O}{O}$ has been built up and a full analysis is available elsewhere. ${ }^{21}$ This paper presents some of the findings $\delta$ of the study.

\section{Methods}

After a three month learning period we entered into the study all 782 patients scanned by the service as part 